\title{
e-Health and telemedicine implementation in facial paralysis: challenges and pitfalls
}

\author{
Elijah E. Sanches ${ }^{1} \cdot$ Frank W. de Jongh ${ }^{1,2} \cdot$ Koen J. A. O. Ingels ${ }^{3} \cdot$ Sjaak Pouwels $^{4}$ (i)
}

Received: 2 November 2020 / Accepted: 2 February 2021 / Published online: 13 February 2021

(C) The Author(s), under exclusive licence to Springer-Verlag GmbH, DE part of Springer Nature 2021

\begin{abstract}
During the current Covid-19 pandemic, a lot of changes had to be made in the care of patients with facial nerve paralysis (FNP). FNP is a life-changing condition with effects on both physical (both esthetic and functional) and psychological aspects of the patient's life. Telemedicine could be a suitable alternative in the therapy for these patients, since it is often not possible to travel to outpatient clinics or to have normal face-to-face appointments with treating physicians because of pandemic restrictions. This review provides an overview of the current literature in the treatment of FNP during the pandemic and the role of telemedicine/e-Health. Secondly, we will discuss the challenges and pitfalls of implementing e-Health and telemedicine applications in clinical practice.

Level of evidence: Not ratable
\end{abstract}

Keywords Facial paralysis $\cdot$ Facial plastic surgery $\cdot$ Telemedicine $\cdot$ Mobile application $\cdot$ Digital $\cdot$ e-Health $\cdot$ Mobile health

\section{Introduction}

A lot of things changed during the current Covid-19 pandemic. One of the most important changes that occurred in the medical world is the enormous rise in the application of "Telemedicine." According to the WHO, telemedicine is literally "healing at a distance," meaning any application of Information Communication Technology (ICT) that can improve patient outcomes by increasing access to care and medical information [1]. There is already a lot of evidence proving the benefits of ICT applications in patient care, especially the positive effects of telemedicine. These positive effects of telemedicine are related to easy accessibility, higher levels of compliance, and improvement in quality of life [2].

Sjaak Pouwels

Sjaakpwls@gmail.com

1 Department of Plastic-, Reconstructive and Hand- Surgery, Haaglanden Medical Center, The Hague, The Netherlands

2 Department of Cardiothoracic Surgery, Haga Hospital, The Hague, The Netherlands

3 Department of Otorhinolaryngology, Head \& Neck Surgery, Radboud University Medical Center, Nijmegen, The Netherlands

4 Department of Intensive Care Medicine, Elisabeth-Tweesteden Hospital, P.O. Box 9051, 5000, LC Tilburg, The Netherlands
Due to several (social distancing) measures during this outbreak, it was impossible for physicians to see patients in the same way as before [3]. Governments advised their inhabitants to stay $1.5 \mathrm{~m}$ (the distance differs in several countries) apart to stop the spread of the disease [4]. Therefore, an increasing need in telemedicine applications arose [5]. In some fields of medicine, telemedicine is already well-developed and patients will get almost the same quality of care that they are used to [2]. The question is: are telemedicine applications, in any form, suitable/applicable on patients afflicted by facial nerve paralysis (FNP). This review provides an overview of the current literature in the treatment of FNP during the pandemic and the role of telemedicine/e-health. Secondly, we will discuss the challenges and pitfalls of implementing e-Health and telemedicine applications in clinical practice.

\section{Telemedicine}

Telemedicine is a relatively new way of practicing medicine which increases in use with ever-growing technical possibilities, which could be very promising, but the reliability of these applications in patients with a facial paralysis needs to be established. Telemedicine has shown promising results and could be a great tool to overcome several barriers that patients face when visiting the hospital, such as geographical and temporal factors [6]. 
The compliance rates after telemedicine are higher in groups undergoing pulmonary rehabilitation and in patients with chronic obstructive pulmonary disease (COPD); there were less emergency department visits and lower hospitalization rates in combination with a decrease in length of stay [7, 8]. The quality of life after telemedicine is equivalent to the standard care or even better in some cases [8]. In very specific groups (patients with medically unexplained pain (MUP)), telemedicine (Internet-based) could decrease the pain intensity, anxiety, stress, and depression [9].

Teleradiology is already part of telemedicine in otolaryngology and this works very well [10]. It is used to exchange radiographic and (relevant) clinical information between, for example, the emergency physicians and the otolaryngologists (who are not present at the hospital) to assess whether there is a clear indication for surgery [10]. Brucoli et al. conducted a retrospective study where 467 patients were triaged in accordance to the abovementioned technique [11]. The CT images were sent to the otolaryngologists for assessment, and of the 467 patients, 223 had no surgical indication, 176 had a possible indication, and 68 had a surgical indication [11]. After clinical assessment, all the surgical and non-surgical patients were in concordance with the teleradiological assessment, and of the possible surgical group, just 27 patients were advised to undergo surgery [11]. There are also several mobile device applications for patients with facial trauma that need an emergency department consult [12]. These applications facilitate remote consulting software, which means that the patients are given the opportunity to consult the emergency department clinicians, without a real-time visit [12]. This could be done by videoconferencing using the camera from the smartphone and/or tablet or by specific software connected to the application [12]. There were several positive aspects in comparison to real-time visits like a 5 -fold quicker response time in comparison to in-person consultations, an overall congruence of treatment recommendation (90.5\%), and there was also an improvement in patient satisfaction rates [12].

Clinicians (both plastic surgeons and otolaryngologists), who treat patients with FNP, use subjective parameters, outcomes, and descriptions to describe patient condition [12]. Often, this non-validated/subjective information is supplemented with nonstandard (medical) photographs [12]. The House-Brackmann scale, often used for FNP patients, was initially developed for patients recovering from vestibular Schwannoma extirpation [12]. That means that there could be errors when applying this method to other diseases causing FNP [12]. Thus, also before the Covid-19 era, there was a problem with adequately assessing the progress of the facial function in patients with a FNP.

Banks et al. developed an application to objectify facial function on a smartphone/laptop/desktop scale use [12]. The result is a useful, objective, visual assessment of FNP that could lead to a universal understanding among clinicians
[12]. Since the application is made for several devices, it could be very useful for both patients and their treating physicians during this pandemic, and since the application is portable, it can be used from anywhere to communicate with their treating physician to interpret the data. Lee et al. stated that an automated, zone-specific facial analysis application could be better than clinical subjectivity and this will be the standardized assessment of FNP [13]. It is possible that in the (near) future, the role of automatic/digital assessments of the progress of FNP in patients could be much larger and even be a part of the standard treatment.

\section{Facial nerve paralysis and the application of e-health}

Facial palsy (paralysis) can be caused by several factors, e.g., viral, iatrogenic, neoplasms, traumatic, and inflammatory [14]. Only in one-third of the cases an exact diagnosis is found [14].

When the seventh cranial nerve (facial nerve, $n$. facialis, or NVII) is damaged, a form of facial nerve paralysis (FNP) could occur [6]. The facial nerve is responsible for the innervation of the mimic muscles, the secretomotor function of several glands (palatine, nasal, salivary, and lacrimal), and the gustatory organ [14]. The most evident symptom of the FNP is facial asymmetry, but FNP also presents with decreased saliva production, changes in taste, dysarthria, and synkinesis (happens when voluntary movements causes involuntary movements of muscle fibers due to erroneously regrowth of the nerve fibers after the initial damage) [14]. Corneal damage and difficulties regarding food manipulation and oral continence can be the consequence [15-23]. FNP also affects the patients psychologically, and this can cause a decrease in self-esteem, reduction of quality-of-life $(\mathrm{QoL})$, anxiety, and depression [15-23]. The impact of a FNP on a patient's life is enormous.

There is also a significant change in facial appreciation in patients with FNP [14]. The symptoms of FNP could have a serious negative effect on patient quality of life [14, 24]. Tieman et al. try to explain several hypotheses about, among others, the facial appreciation of patients with FNP [14].

The House-Brackmann grading scale is used to scale the clinical severity of the disease on a six-point scale [14, 25]. Besides the House-Brackmann grading scale, there are two more systems that are used for the clinical evaluation of FNP. Firstly, there is the Sunnybrook facial grading system [26]. This system composes a 100-point scale based on the patients resting symmetry, synkinesis of the patients face, and 5 predetermined facial movements (forehead wrinkle, gentle eye closure, open mouth smile, snarl, and lip pucker) [26]. The third rating system is predominantly used in the Oceania area [26]. The Sydney system assesses the five facial nerve branches and their voluntary movements and synkinesis [26]. 
Due to the Covid-19 pandemic, there is a transition from traditional way of care to more modern ways. Due to all measurements that are taken to protect public health, there is an enormous rise in the application of telemedicine and especially e-health [26-28]. Eysenbach et al. stated that e-health is "an emerging field in the intersection of medical informatics, public health and business, referring to health services and information delivered or enhanced through the Internet and related technologies" [29].

$\mathrm{m}$-Health (mobile health) is a component of e-health and is defined by the Global Observatory for e-Health (GOe) as medical and public health practice supported by mobile devices, such as mobile phones, patient monitoring devices, personal digital assistants (PDAs), and other wireless devices [30].

In plastic surgery, there are already several studies done to evaluate the effects of telemedicine/e-Health/m-Health [30-35]. In the systematic review by Vyas et al., the conclusion was that telemedicine improved postoperative monitoring, while lowering the costs. Besides this, it also increased the possibility to access expertise [35]. Telemedicine is now used in several disciplines in plastic surgery like wound management, burn management, trauma, free-flap care, cleft/palate repair, hand surgery, and maxillofacial. In the field of FNP, there are several forms of telemedicine used, but the results are still varying [6]. Tan et al. mentioned that in the specific field of FNP and telemedicine, there were not a lot of (large) studies conducted and most of the literature is on clinicians who implemented the techniques, without formal studies [6]. Therefore, Tan conducted an exploratory study to compare the reliability of the HouseBrackmann, Sunnybrook, and Sydney facial grading systems in real life vs assessing pre-recorded videos [6]. The study concluded that the reliability of the three facial grading systems was mostly similar in the assessment of both groups, except for assessing synkinesis, on which the second group scored worse [6]. Although the videos were of 2D quality and the real-life assessment was of 3D quality, this did not bother the comparison [6]. However, both ways of assessing are mostly reliable; the differences are clinically too relevant to state that FNP patients could use telemedicine as substitute for real-life consultations [6].

Attempts have been made to assess facial asymmetry in a fast and non-invasive way using the VECTRA M3 stereophotogrammetric system, providing viable quantitative information in diagnosing, treatment planning, and evaluation [36]. Since 2D pictures do provide information on movement, $2 \mathrm{D}$ video lacks the anterior-posterior axis, there are now commercially available $3 \mathrm{D}$ video cameras which are important in judging faces [37-42]. Ten Harkel et al. [26] explored the possibility of an economically viable telemedicine 3D imaging system for home use. The RealSense F200 4D camera was chosen for its portability, its relatively low cost, and its ability to capture the anteriorposterior axis in facial movement $[26,43]$.
In 2014, the eFACE application was designed and validated by Banks et al. [12, 44]. This is a comprehensive, electronic, and clinician-graded facial function scale that assesses a visual scale of facial function using 3 parameters consisting of 5 static, 7 dynamic, and 4 synkinesis items [12, 44]. It uses smartphone or pc technology and provides relevant data to all practitioners involved. The authors found that the eFACE scores demonstrated very high inter-rater and intra-rater reliability in experienced facial nerve clinicians and that its ease in utility and continuous disfigurement scale provides a tool for facial palsy research and treatment $[12,44]$. This was then tested whereas facial nerve clinicians to score and rescore these clips, providing positive results, since the participants were eager to apply the application in clinical practice, tested 30 FNP patient videos [44].

\section{Challenges and pitfalls}

Like all new techniques, telemedicine also has challenges or aspects that could be improved in the (near) future. In the next part of this review, the current challenges and pitfalls of the (an accelerative) implementation of telemedicine will be addressed.

\section{Pitfalls that are present when the implementation is rushed}

This is the first time that the world faces a pandemic of this magnitude, but during the earlier outbreaks, SARS-CoV, MERS-CoV, Ebola, and Zika were already experimented with a conceptual framework for telemedicine [27]. The first version was published in 2015. Ohannessian et al. [27] made a new framework especially for the Covid-19 outbreak. In the ideal situation, telemedicine is implemented when there is high-speed Internet available and there is a high number of smartphone ownership in the country [27]. However, a lot countries do not have a regulatory framework to implement (authorize, integrate, and reimburse) telemedicine quickly, particularly in emergency or outbreak situations [27, 45].

A problem that could arise with technology used for telemedicine is that if healthcare workers use free and convenient solutions for video calls like WhatsApp, Facetime, Zoom, or Skype; there is no control on national health data and privacy.

Another pitfall is the reimbursement, because not all countries reimburse telemedicine, while this is an essential part for the implementation of e-Health [27].

Besides the previously mentioned aspects, the following points need to be taken into account: (1) a data sharing network between telemedicine providers and epidemiological surveillance, (2) scientific evaluation of the telemedicine framework, (3) a campaign to inform the population on the use of telemedicine [27]. 
Bashshur et al. [46] stated that because of the rapid implementation of telemedicine, the technology is not optimal and therefore care is also suboptimal. Both patients and caregivers are not familiar with this medium of communication, and this suboptimal knowledge of the system will have a negative effect on the quality of care [46].

\section{Current ICT-network and applications}

Since telemedicine is "Internet-based," connectivity, video resolution, and sound quality should be guaranteed at all times. This provides difficulties in especially rural and lowincome communities [47]. In those areas, there is not enough network accommodation because of low financial benefits, lack of legal requirements, and the lack of incentive for the private providers [47]. The use of smartphones is still rising and even "older" smartphones can be used for the implementation of e-Health (mobile-Health or m-Health). In The Netherlands and the USA, currently (2018) $87 \%$ and $81 \%$ of the population own a smartphone, respectively [48-50]. So, this could be an outcome for people living in rural areas, because there are no big differences in smartphone ownership in urban and rural areas, $83 \%$ vs $73 \%$, respectively [48].

There is also a group of patients that could face difficulties with the implementation of widespread e-Health. This group are the (ICT)-illiterates [47, 51]. These groups have trouble reading and/or using any ICT tools, which could lead to "medical-isolation" [47, 51]. If this group visited the treating physician at an outpatient clinic, there were less barriers and less chance at medical isolation. This is especially true for the elderly patients.

Also, for some disabled patients, difficulties arise to have the same standard of care in telemedicine, because of the accessibility could be worse if you look at screen reader, magnification, colors and contrast, and sign language [47]. Devices used by FNP patients with other disabilities therefore require customization options, such as proper tele-evaluation through cameras or other measurement devices [47].

In some countries, there are also regulatory barriers that have been eased during the pandemic, which could be revoked when the pandemic ends [47]. Maybe those barriers could make it harder to implement telemedicine.

\section{Imbursement and legal aspects}

There are three main rights that patients have been looking at telemedicine [52]. Patients have the right to be reimbursed, the right of access to the report, and the opportunity to check the quality of services [52]. Basically, the same rights need to apply when going to the local healthcare facility.

The EU legal framework for telemedicine is revised. Several rights were added in comparison with the earlier legal framework, such as "The right to be forgotten," "The right that the needs to minimal," and the "Right not to be anonymised." Next to these rights, patients always have the right to demand that all their personal information need to be erased [52]. See Table 1 for a clear overview of the current legal framework in the European Union regarding telemedicine $[11,53,54]$.

For telemedicine information, the same standard holds as for regular medical information, namely that patient's
Table 1 Overview of the current legal framework in the European Union regarding telemedicine $[11,53,54]$
Current EU legislation to telemedicine

1. "Telemedicine is both a health service and an information society service."

2. "Freedom for recipients of the healthcare service to seek and receive medical treatment from another member state, regardless of how the service is delivered, i.e., also by telemedicine."

3. "If member states adopt new laws, regarding technical regulations and information services (e.g., telemedicine), they are obliged to notify the European Commission."

4. "Professional-to-professional telemedicine services are conducted to the laws of the country of the sending professional. Professional-to-patient telemedicine services need to be according to the law of the country of the patient (recipient)."

5. "The definition of a medical act is a matter for the member states. As a general principle, it is stated that the telemedicine equivalent of the conventional medical service (e.g., teleradiology vs radiology) needs to adhere to the same requirements as the conventional service. Otherwise, it would be possible that poorly regulated telemedicine equivalents would replace the highly regulated conventional methods."

6. "Regarding the handling of personal data and the protection of privacy, there are the same requirements as all other interactive on-line services."

7. "In addition to the abovementioned point regarding personal data and privacy, there are specific requirements for the providers of electronic communication services to ensure confidentiality of communication and security of the network."

8. "There are criteria for specific professions with qualifications in one member state, so that they could gain access (via telemedicine) in other member states to the same profession." 
information only can be send or shared with (explicit) consent of the patient [52]. Patients have the right to check the quality of the service, and for this reason, the name of the physician who's involved with the telemedicine procedure needs to be included in the report [52].

\section{Conclusions}

Telemedicine will probably never completely replace the "old-fashioned"/ conventional way of practicing medicine, but it will be a proper complementary tool to elevate the levels of patient care. Telemedicine is relatively new, and it will take time to let it work properly in all types of specialties. Looking at the FNP, there are some promising tools for the near future that could be used during this pandemic, the possible 2nd wave and probably the time after everything is returned to normal. It could be a way to lower the healthcare costs and to make healthcare more accessible for a larger group of patients. Despite the fact that most of the techniques are still in their infancy, they could very promising in the (near) future. The current pandemic provides momentum to prove the everincreasing capabilities of telemedicine and should be used to provide adequate evidence so telemedicine remains a growing field of study even after the pandemic ends.

\section{Declarations}

Ethics approval For this type of review study formal consent from a local ethics committee is not required.

Conflict of interest Elijah E. Sanches, Frank W. de Jongh, K.J.A.O. Ingels, and Sjaak Pouwels declare no conflict of interest.

Informed consent Not applicable

\section{References}

1. WHO: Telemedicine. Available from: https://www.who.int/goe/ publications/goe_telemedicine_2010.pdf

2. Russell TG, Hoffmann TC, Nelson M, Thompson L, Vincent A (2013) Internet-based physical assessment of people with Parkinson disease is accurate and reliable: a pilot study. J Rehabil Res Dev 50(5):643-650

3. WHO: Protect yourself and others from the spread COVID-19 Available from: https://www.who.int/emergencies/diseases/novelcoronavirus-2019/advice-for-public

4. Tackling new coronavirus in the Netherlands. Available from: https://www.government.nl/topics/coronavirus-covid-19/tacklingnew-coronavirus-in-the-netherlands

5. Hunt TLI, Hooten WM (2020) The effects of COVID-19 on telemedicine could outlive the virus. Mayo Clin Proc Innov Qual Outcomes 4:583-585
6. Tan JR, Coulson S, Keep M (2019) Face-to-face versus video assessment of facial paralysis: implications for telemedicine. J Med Internet Res 21(4):e11109

7. Lundell S, Holmner A, Rehn B, Nyberg A, Wadell K (2015) Telehealthcare in COPD: a systematic review and meta-analysis on physical outcomes and dyspnea. Respir Med 109(1):11-26

8. Polisena J, Tran K, Cimon K, Hutton B, McGill S, Palmer K (2010) Home telehealth for chronic obstructive pulmonary disease: a systematic review and meta-analysis. J Telemed Telecare 16(3):120 127

9. Chavooshi B, Mohammadkhani P, Dolatshahi B (2016) A randomized double-blind controlled trial comparing Davanloo intensive short-term dynamic psychotherapy as internet-delivered vs treatment as usual for medically unexplained pain: a 6-month pilot study. Psychosomatics. 57(3):292-300

10. Said M, Ngo V, Hwang J, Hom DB (2020) Navigating telemedicine for facial trauma during the COVID-19 pandemic. Laryngoscope Investig Otolaryngol 5(4):649-656

11. Brucoli M, Boffano P, Franchi S, Pezzana A, Baragiotta N, Benech A (2019) The use of teleradiology for triaging of maxillofacial trauma. J Craniomaxillofac Surg 47(10):1535-1541

12. Banks CA, Bhama PK, Park J, Hadlock CR, Hadlock TA (2015) Clinician-graded electronic facial paralysis assessment: the eFACE. Plast Reconstr Surg 136(2):223e-230e

13. Lee LN, Susarla SM, Hohman MH, Henstrom DK, Cheney ML, Hadlock TA (2013) A comparison of facial nerve grading systems. Ann Plast Surg 70(3):313-316

14. Tieman TE, Chaiet SR, Luijmes R, Sanches E, de Jongh FW, Ingels $K$ et al (2020) A closer look at the paralyzed face: a narrative review of the neurobiological basis for functional and aesthetic appreciation between patients with a left and a right peripheral facial palsy. J Plast Reconstr Aesthet Surg 73(8):1434-1441

15. Coulson SE, O'Dwyer NJ, Adams RD, Croxson GR (2004) Expression of emotion and quality of life after facial nerve paralysis. Otol Neurotol 25(6):1014-1019

16. Fu L, Bundy C, Sadiq SA (2011) Psychological distress in people with disfigurement from facial palsy. Eye (Lond) 25(10):13221326

17. Eviston TJ, Croxson GR, Kennedy PG, Hadlock T, Krishnan AV (2015) Bell's palsy: aetiology, clinical features and multidisciplinary care. J Neurol Neurosurg Psychiatry 86(12):1356-1361

18. Fattah AY, Gurusinghe ADR, Gavilan J, Hadlock TA, Marcus JR, Marres H, Nduka CC, Slattery WH, Snyder-Warwick AK, Sir Charles Bell Society (2015) Facial nerve grading instruments: systematic review of the literature and suggestion for uniformity. Plast Reconstr Surg 135(2):569-579

19. Chong LSH, Eviston TJ, Low TH, Hasmat S, Coulson SE, Clark JR (2017) Validation of the clinician-graded electronic facial paralysis assessment. Plast Reconstr Surg 140(1):159-167

20. Eren SB, Dogan R, Ozturan O, Veyseller B, Hafiz AM (2017) How deleterious is facial nerve dissection for the facial nerve in parotid surgery: an electrophysiological evaluation. J Craniofac Surg 28(1): $56-60$

21. Gaudin RA, Robinson M, Banks CA, Baiungo J, Jowett N, Hadlock TA (2016) Emerging vs time-tested methods of facial grading among patients with facial paralysis. JAMA Facial Plast Surg 18(4):251-257

22. Volk GF, Granitzka T, Kreysa H, Klingner CM, Guntinas-Lichius O (2017) Initial severity of motor and non-motor disabilities in patients with facial palsy: an assessment using patient-reported outcome measures. Eur Arch Otorhinolaryngol 274(1):45-52

23. Helwig NE, Sohre NE, Ruprecht MR, Guy SJ, Lyford-Pike S (2017) Dynamic properties of successful smiles. PLoS One 12(6): e0179708

24. Luijmes RE, Pouwels S, Beurskens CH, Kleiss IJ, Siemann I, Ingels KJ (2017) Quality of life before and after different treatment 
modalities in peripheral facial palsy: a systematic review. Laryngoscope. 127(5):1044-1051

25. Bascom DA, Schaitkin BM, May M, Klein S (2000) Facial nerve repair: a retrospective review. Facial Plast Surg 16(4):309-313

26. Ten Harkel TC, Speksnijder CM, van der Heijden F, Beurskens CHG, Ingels K, Maal TJJ (2017) Depth accuracy of the RealSense F200: low-cost 4D facial imaging. Sci Rep 7(1):16263

27. Ohannessian R, Duong TA, Odone A (2020) Global telemedicine implementation and integration within health systems to fight the COVID-19 pandemic: a call to action. JMIR Public Health Surveill 6(2):e18810

28. Wynn R (2020) E-Health in Norway before and during the initial phase of the Covid-19 pandemic. Stud Health Technol Inform 272: 9-12

29. Eysenbach G (2001) What is e-health? J Med Internet Res 3(2):E20

30. WHO: mHealth New horizons for health through mobile technologies. Available from: https:/www.who.int/goe/publications/goe_ mhealth web.pdf

31. Kantor J (2017) Telemedicine: from microsurgery and free flaps to total body skin Examination. Ann Plast Surg 79(4):415

32. Gardiner S, Hartzell TL (2012) Telemedicine and plastic surgery: a review of its applications, limitations and legal pitfalls. J Plast Reconstr Aesthet Surg 65(3):e47-e53

33. Hsieh CH, Tsai HH, Yin JW, Chen CY, Yang JC, Jeng SF (2004) Teleconsultation with the mobile camera-phone in digital softtissue injury: a feasibility study. Plast Reconstr Surg 114(7):17761782

34. Hee Hwang J, Mun GH (2012) An evolution of communication in postoperative free flap monitoring: using a smartphone and mobile messenger application. Plast Reconstr Surg 130(1):125-129

35. Vyas KS, Hambrick HR, Shakir A, Morrison SD, Tran DC, Pearson K, Vasconez HC, Mardini S, Gosman AA, Dobke M, Granick MS (2017) A systematic review of the use of telemedicine in plastic and reconstructive surgery and dermatology. Ann Plast Surg 78(6):736-768

36. Codari M, Pucciarelli V, Stangoni F, Zago M, Tarabbia F, Biglioli F, Sforza C (2017) Facial thirds-based evaluation of facial asymmetry using stereophotogrammetric devices: application to facial palsy subjects. J Craniomaxillofac Surg 45(1):76-81

37. Turkstra LS, Quinn-Padron M, Johnson JE, Workinger MS, Antoniotti N (2012) In-person versus telehealth assessment of discourse ability in adults with traumatic brain injury. J Head Trauma Rehabil 27(6):424-432

38. Demiris G, Oliver DP, Wittenberg-Lyles E, Washington K (2011) Use of videophones to deliver a cognitive-behavioural therapy to hospice caregivers. J Telemed Telecare 17(3):142-145

39. Ward EC, Sharma S, Burns C, Theodoros D, Russell T (2012) Validity of conducting clinical dysphagia assessments for patients with normal to mild cognitive impairment via telerehabilitation. Dysphagia. 27(4):460-472

40. Ward EC, Sharma S, Burns C, Theodoros D, Russell T (2012) Managing patient factors in the assessment of swallowing via telerehabilitation. Int J Telemed Appl 2012:132719
41. Vranceanu AM, Riklin E, Merker VL, Macklin EA, Park ER, Plotkin SR (2016) Mind-body therapy via videoconferencing in patients with neurofibromatosis: an RCT. Neurology. 87(8):806814

42. Luxton DD, Pruitt LD, Wagner A, Smolenski DJ, JenkinsGuarnieri MA, Gahm G (2016) Home-based telebehavioral health for U.S. military personnel and veterans with depression: a randomized controlled trial. J Consult Clin Psychol 84(11):923-934

43. Coulson SE, Croxson GR, Gilleard WL (2000) Quantification of the three-dimensional displacement of normal facial movement. Ann Otol Rhinol Laryngol 109(5):478-483

44. Banks CA, Jowett N, Azizzadeh B, Beurskens C, Bhama P, Borschel $\mathrm{G}$ et al (2017) Worldwide testing of the eFACE facial nerve clinician-graded scale. Plast Reconstr Surg 139(2):491e$498 \mathrm{e}$

45. Smith AC, Thomas E, Snoswell CL, Haydon H, Mehrotra A, Clemensen J, Caffery LJ (2020) Telehealth for global emergencies: implications for coronavirus disease 2019 (COVID-19). J Telemed Telecare 26(5):309-313

46. Bashshur RL, Mandil SH, Shannon GW (2002) Telemedicine/ telehealth: an international perspective. Executive summary. Telemed J E Health 8(1):95-107

47. Annaswamy TM, Verduzco-Gutierrez M, Frieden L (2020) Telemedicine barriers and challenges for persons with disabilities: COVID-19 and beyond. Disabil Health J 13(4):100973

48. Available from: https://www.pewresearch.org/internet/fact-sheet/ mobile/

49. Lamirel C, Bruce BB, Wright DW, Newman NJ, Biousse V (2012) Nonmydriatic digital ocular fundus photography on the iPhone 3G: the FOTO-ED study. Arch Ophthalmol 130(7):939-940

50. meeste-nederlanders-beschermen-gegevens-op-smartphone Available from: https://www.cbs.nl/nl-nl/nieuws/2019/06/meestenederlanders-beschermen-gegevens-op-smartphone

51. Al-Samarraie H, Ghazal S, Alzahrani AI, Moody L (2020) Telemedicine in Middle Eastern countries: progress, barriers, and policy recommendations. Int J Med Inform 141:104232

52. European Society of Radiology (ESR) (2014) ESR white paper on teleradiology: an update from the teleradiology subgroup. Insights Imaging 5(1):1-8. https://doi.org/10.1007/s13244-013-0307-z

53. eHealth Action Plan 2012-2020: Innovative healthcare for the 21st century. Available from: https://ec.europa.eu/digital-single-market/ en/news/ehealth-action-plan-2012-2020-innovative-healthcare21st-century

54. (2008) Communication from the commission to the European Parliament, the council, the European economic and social committee and the committee of the regions on telemedicine for the benefit of patients, healthcare systems and society. Available from: https:// eur-lex.europa.eu/LexUriServ/LexUriServ.do?uri=COM:2008: 0689:FIN:EN:PDF

Publisher's note Springer Nature remains neutral with regard to jurisdictional claims in published maps and institutional affiliations. 